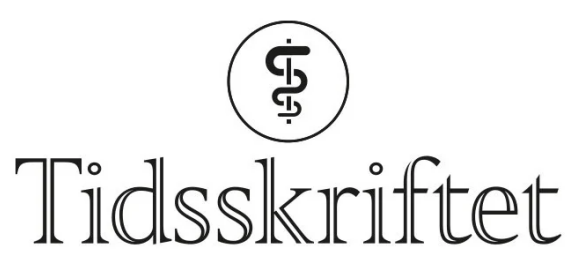

DEN NORSKE LEGEFORENING

\title{
En introduksjon til forløpsbasert finansiering
}

KRONIKK

\section{CHRISTER MJÅSET}

chrmja@gmail.com

Christer Mjåset er spesialist i nevrokirurgi og Harkness fellow i Health Care Policy and Practice 201920 ved Harvard T.H. Chan School of Public Health og The Commonwealth Fund.

Forfatteren har fylt ut ICMJE-skjemaet og oppgir ingen interessekonflikter.

\section{HALDOR BYRKJEFLOT}

Haldor Byrkjeflot er professor ved Institutt for sosiologi og samfunnsgeografi ved Universitetet i Oslo og gjesteforsker ved Weatherhead Center for International Affairs, Harvard University. Forfatteren har fylt ut ICMJE-skjemaet og oppgir ingen interessekonflikter.

\section{FREDRIK A.S.R. HANSSEN}

Fredrik A.S.R. Hanssen er avdelingsdirektør i Helsedirektoratets avdeling for finansiering. Han er lege med klinisk bakgrunn i indremedisin og har arbeidet med klassifisering, aktivitetsmåling og finansiering av helsetjenester.

Forfatteren har fylt ut ICMJE-skjemaet og oppgir ingen interessekonflikter.

\section{WILLIAM WYNN-JONES}

William Wynn-Jones er britisk anestesiolog og helsetjenesteforsker tilknyttet Center for Surgery and Public Health ved Brigham and Women's Hospital i Boston, der han også var Harkness fellow i 201718.

Forfatteren har fylt ut ICMJE-skjemaet og oppgir ingen interessekonflikter.

\section{2019 ble forløpsbasert finansiering innført for første gang i den norske helsetjenesten. I denne artikkelen gjennomgår vi den historiske bakgrunnen og kunnskapsgrunnlaget for denne finansieringsordningen, som i økende grad tas i bruk både i USA og over hele Europa.}

I Nasjonal helse- og sykehusplan 2020-23 ble forløpsbasert finansiering presentert som en $\emptyset n s k e t$ utviklingsretning for finansering av den norske helsetjenesten. Idéen bak denne ordningen er å tilby en samlet refusjon for alle de omsorgselementene som faller innenfor et forhåndsbestemt pasientforløp eller en klinisk behandlingsepisode. Det legges også opp til at hvert pasientforløp kan knyttes opp til spesifikke måltall for å sikre at kvaliteten på 
tjenestene opprettholdes og for å legge til rette for å kunne belønne god kvalitet. Samtidig inndeles pasientgrupper etter risikoprofil for å forhindre at de leverandørene som behandler de sykeste pasientene, straffes økonomisk.

Tilhengerne av forløpsbasert finansering hevder at ordningen representerer en forbedring av den innsatsstyrte finansieringsordningen som har vært anvendt i Norge de siste tiårene (1). I denne artikkelen ser vi nærmere på den historiske bakgrunnen for forløpsbasert finansiering og hva eksisterende forskning sier om fordelene og ulempene ved ordningen. Vi stiller også spørsmålet om hvorvidt - og hvordan - det fungerer å ta i bruk en slik ordning i et offentlig finansiert helsevesen som det norske.

\section{Diagnoserelaterte grupper}

Tidlig i 1980-årene var refusjonene til helsetjenesteleverandører i USA nesten utelukkende basert på betaling for alle deltjenester (fee-for-service). Dette ga sterke insentiver til

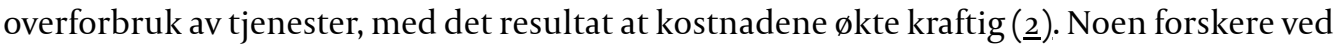
Yale University satte seg som mål å lage et system som skulle motivere til raskere utskriving av pasienter og dermed dempe forbruket av tjenester i det føderale forsikringsprogrammet Medicare (3). Ved å basere godtgjørelser for ulike pasientgrupper på historiske gjennomsnittskostnader i forbindelse med sykehusinnleggelser, ble systemet med diagnoserelaterte grupper (DRG) etablert. På sikt skulle DRG-systemet vise seg å gi en voldsom økning i antallet pleieinstitusjoner i USA, fordi sykehusene av økonomiske årsaker prioriterte å sende pasientene videre heller enn å beholde dem til de var friske nok til å sendes hjem. Dette fenomenet er noe Medicare fortsatt sliter med den dag i dag (4).

Selv om tanken bak innføringen av DRG-systemet var å gjøre amerikanske sykehus mer ansvarlige for egne pasienter, skulle systemet komme til å tjene andre formål da det ble introdusert i Norge i 1990-årene. Den norske helsetjenesten var da i all hovedsak rammefinansiert, og innføringen av diagnoserelaterte grupper innebar en endring til en mer aktivitetsbasert og innsatsstyrt modell. Målet var å stimulere til mer produktivitet og effektivitet på sykehusene samt begrense kostnadsveksten (므).

\section{«Resultatene er mindre gode for medisinske behandlingsforløp sammenlignet med kirurgiske»}

I 1997 ble DRG-systemet innført som en obligatorisk del av sykehusfinansieringen i Norge (2). . På denne tiden hadde man fått mer erfaring med de utilsiktede effektene av DRG-bruk internasjonalt, deriblant at sykehus stimuleres til å redusere kostnader uten nødvendigvis å kontrollere hva det har å si for kvaliteten. Det var også blitt åpenbart at DRG ikke ga gode nok insentiver til samarbeid på tvers av enheter og tjenestenivåer (5).

I USA førte denne innsikten til videre eksperimentering både i privat og offentlig sektor, og det ble etablert enkeltrefusjoner for lengre omsorgssykluser på tvers av ulike tjenesteleverandører. Et viktig steg i utviklingen ble å peke ut én leverandør som hovedansvarlig for samarbeid og økonomi. Denne leverandøren ble så gjort kontraktmessig ansvarlig for en omsorgsperiode som kunne utvides til 30-9o dager og omfatte både oppfølgende konsultasjoner og reinnleggelser etter utskriving (figur 1) (ㅁ). Til sist ble det innført kvalitetsmål for å sikre at leverandørene opprettholdt kvaliteten på omsorgen. Disse har tradisjonelt vært strukturelle mål, slik som reinnleggelses- eller komplikasjonsrater - eller sågar mortalitetsrater. I de senere årene har man i økende grad vektlagt å måle pasientutfall, som for eksempel pasientrapporterte utfallsmål (patientreported outcome measures) (.7.). 


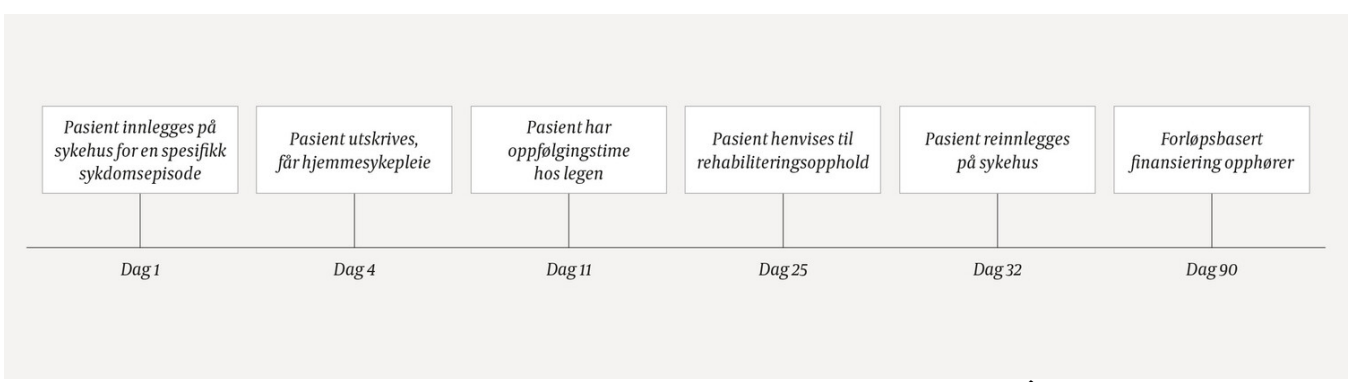

Figur 1 Eksempel på et pasientforløp med forløpsbasert finansiering. Én leverandør er hovedansvarlig for samarbeid og $ø$ konomi, og for en omsorgsperiode som kan utvides til 30-90 dager og omfatte både oppfølgende konsultasjoner og reinnleggelser.

\section{Obamas helselov}

I forbindelse med vedtaket av helseloven The Affordable Care Act, eller Obamacare, i 2010 ble forløpsbasert finansiering løftet frem som et viktig middel for å reformere den amerikanske helsetjenesten. Ambisjonen var at denne typen finansiering skulle erstatte store deler av de innsatsstyrte finansieringsordningene som dominerte helsemarkedet ( $\underline{8})$. Dette skiftet har gått langsommere enn planlagt, men Medicare har likevel lansert en rekke landsomfattende forløpsbaserte finansieringsprogrammer de senere årene. De ulike programmene dekker typisk et pasientforløp på go dager og utløses gjerne av at en pasient blir innlagt på sykehus (tabell 1) (9).

\section{Tabell 1}

Noen av de nye og løpende forløpsbaserte betalingsprogrammene under Medicare i USA. $\mathrm{BPCI}=$ Bundled Payments for Care Improvement, $\mathrm{CJR}=$ Comprehensive Care for Joint Replacement. All informasjon er hentet fra www.cms.gov.

\begin{tabular}{|c|c|c|c|}
\hline Parameter & $\mathrm{BPCI}$ & BPCI Advanced & CJR \\
\hline Deltagelse & Frivillig & Frivillig & Obligatorisk \\
\hline Tidsperiode & $2013-18$ & $2018-23$ & $2016-21$ \\
\hline Region & Nasjonalt & Nasjonalt & 67 utvalgte områder \\
\hline Kliniske episoder & 48 episodetyper & $\begin{array}{l}29 \text { innlagte og } \\
3 \text { polikliniske }\end{array}$ & $\begin{array}{l}\text { Hofte- og } \\
\text { kneprotesekirurgi }\end{array}$ \\
\hline Episodelengde & $30 / 60 / 90$ dager & 90 dager & 90 dager \\
\hline Avregning & Kvartalsvis & Halvårlig & Årlig \\
\hline Risikostratifisering & Ja & Ja & Ja \\
\hline Beregning av målpris & $\begin{array}{l}\text { Basert på } \\
\text { deltagerens } \\
\text { historiske kostnader }\end{array}$ & $\begin{array}{l}\text { Basert på } \\
\text { leverandørens } \\
\text { historiske kostnader } \\
\text { med justering for } \\
\text { pasientmiks (case- } \\
\text { mix) og andre } \\
\text { faktorer på } \\
\text { leverandørnivå }\end{array}$ & $\begin{array}{l}\text { Basert på en } \\
\text { blanding av } \\
\text { sykehusspesifikke og } \\
\text { regionale } \\
\text { episodedata }\end{array}$ \\
\hline $\begin{array}{l}\text { Stopp tap/stopp } \\
\text { fortjenestegrenser }\end{array}$ & $\begin{array}{l}+/-20 \% \text { av } \\
\text { målprisen }\end{array}$ & $\begin{array}{l}+/-20 \% \text { av } \\
\text { målprisen }\end{array}$ & $\begin{array}{l}\text { Fra } 0 \% \text { til +/- } 20 \% \\
\text { av målpris avhengig } \\
\text { av tidspunkt og } \\
\text { lokalisasjon }\end{array}$ \\
\hline
\end{tabular}


Fordi Medicare er en trendsetter i helsemarkedet, har også private forsikringsselskaper i den senere tid begynt å tilby forløpsbaserte betalingsmodeller. I 2018 var $36 \%$ av alle helserefusjoner i USA knyttet til såkalte alternative modeller, mens de resterende fortsatt er innsatsstyrte (10 $)$.

\section{Prissetting og design}

En av de viktigste driverne bak innføringen av forløpsbasert finansiering er ønsket om å legge ansvaret for overforbruk av helsetjenester over på tjenesteleverandørene. Denne ansvarsforskyvningen gjør at leverandørene tvinges til å revurdere aktiviteten sin og forbedre koordineringen og samarbeidet mellom egne avdelinger og andre institusjoner. Hvordan og i hvilken grad leverandørene blir holdt ansvarlige, avhenger av hvordan ordningen er designet og hvordan forløpet prises.

Prisen på et forløp skal dekke alle utgiftene til en tjenesteleverandør for en pasient for en gitt omsorgsperiode. I USA er det vanlig med såkalte retrospektive betalingsmodeller. Det innebærer at leverandøren fortløpende fakturerer forsikringsselskapet for tjenester som utføres underveis i en behandling. I etterkant legges så alle beløpene sammen for å kunne sammenlignes med den forhåndsbestemte prisen. Hvis utbetalingene til en leverendør er lavere enn avtalt, vil leverandøren motta full eller delvis refusjon tilsvarende diskrepansen mellom det avtalte og det fakturerte beløpet. Hvis leverandøren derimot har fakturert for mer enn den avtalte prisen, kan forsikringsselskapet kreve at leverandøren betaler hele eller deler av det overskytende beløpet tilbake. Enkelte hevder at slik straff er avgjørende for å kunne motivere til omlegging og bedre koordinering av omsorg (1ㅡ). For å begrense risikoen til en viss grad kan det innføres en stopp tap-grense (stop loss limit) for de deltagende institusjonene, noen ganger også en stopp fortjeneste-grense (stop gain limit).

«For dialyse gir den gjennomsnittsbaserte prisingen økt insentiv til å foreta dialyse i hjemmet $i$ stedet for ved en institusjon»

En annen viktig faktor som påvirker leverandørenes risiko, er hvordan godtgjørelsen for et gitt forløp utregnes. I Medicares opprinnelige Bundled Payment for Care Improvementprogram fikk hver av leverandørene tilbudt godtgjørelser som var noe lavere enn hva de hadde fått i sum for samme type tjenester forut for deltagelse (tabell 1). Meningen var å få leverandørene til å kostnadseffektivisere driften samtidig som de opprettholdt kvaliteten på tjenestene (9.). Dette betydde også at den relative forskjellen i godtgjørelser til hver av leverandørene forble omtrent den samme. De som hadde kuttet driftskostnader forut for deltagelse, kom altså dårligere ut økonomisk enn de som ikke hadde gjort det.

En behandlingsgodtgjørelse kan baseres på den gjennomsnittlige prisen i et geografisk område. Også dette har ulemper. Leverandører med lave pasientvolum og allerede store kostnader i forhold til den fastsatte prisen vil da kunne ha vanskelig for å komme inn under et egnet kostnadsnivå - rett og slett fordi effektiviseringspotensialet er for lite.

Det kan til slutt være viktig å dele inn pasienter i ulike risikogrupper når man avtaler betingelser knyttet til fullfinansierte forløp. Tar man ikke hensyn til at pasienter med komplekse sykdomsbilder gjerne har et høyere forbruk av helsetjenester, vil leverandører med en stor andel av slike pasienter kunne få problemer med å drifte lønnsomt. Uten risikoinndeling vil også de leverandørene som «skummer fløten» blant de friskeste pasientene, kunne komme svært godt ut økonomisk, fordi slike pasienter vil være forbundet med mindre kostnader enn det som er lagt til grunn i ordningen.

\section{Hva viser kunnskapen fra USA?}


Både amerikanske helsemyndigheter og private forsikringsselskaper har gjennomført løpende evalueringer av de forløpsbaserte finansieringsordningene som er blitt innført de senere årene.

Resultatene av disse evalueringene viser at forløpsbaserte finansieringsordninger reduserer kostnadene og opprettholder eller forbedrer behandlingskvaliteten for prosedyrebaserte kirurgiske inngrep. Tallene er best for hofte- og kneleddsoperasjoner, som er blant de inngrepene som hyppigst inngår i slike ordninger. Forløpsbaserte finansieringsordninger for andre prosedyrer har gått i $\varnothing$ konomisk balanse uten at kvaliteten forringes. Dette gjelder blant annet rygginngrep og koronare bypassoperasjoner (12).

Generelt sett er resultatene mindre gode for medisinske behandlingsforl $ø \mathrm{p}$ sammenlignet med kirurgiske. I en nylig gjennomført studie fant man ingen endringer i Medicareutbetalinger for fem av de vanligste indremedisinske tilstandene etter overgang til forløpsbasert finansiering (13). Én grunn til dette kan være at de største innsparingene ved forløpsbasert finansiering har vist seg å være knyttet til redusert bruk av rehabilitering og postakutt pleie, noe som ofte spiller en større rolle i prosedyrebaserte forløp. For en hjertesviktpasient, derimot, vil innsparingspotensialet ligge i å unngå en sykehusinnleggelse heller enn å redusere rehabiliteringsoppholdet i den postakutte fasen. Enkelte mener derfor at finansieringen av indremedisinske forløp ikke bør utløses av en sykehusinnleggelse, men heller kobles til episoder eller forhold der pasienten fortsatt er under oppfølging i primærhelsetjenesten (14.).

Det skal noteres at amerikansk forskning på forløpsbasert finansiering først og fremst har blitt gjort på Medicare-pasienter som er over 65 år. Resultatene trenger derfor ikke være valide i systemer der myndighetene tilbyr helseforsikring til folk i alle aldre. Kvalitative studier tyder også på at leverandører opplever betydelige effektivitetsgevinster og kvalitetsforbedringer ved deltagelse i forløpsbaserte finansieringsordninger (15).

\section{Overføring til europeiske systemer}

Flere europeiske land er i ferd med å implementere forløpsbaserte finansieringordninger, selv om det frem til nå er forsket lite på hva disse modellene har å si for kostnads- og kvalitetsnivået i de ulike helsetjenestene.

I Sverige har man innført forløpsbasert finansiering for en rekke ortopediske inngrep. Disse ordningene ligner på de som er innført i den amerikanske spesialisthelsetjenesten (16). Nederland har mer enn ti års erfaring med forløpsbasert finansiering i primærhelsetjenesten (17.). Argumentet for et slikt fokus er at man på dette omsorgsnivået i større grad vil kunne fokusere på forebygging av sykehusinnleggelser, mens de mer prosedyrebaserte modellene er rettet mot å hindre reinnleggelser og minske behovet for postakutt behandling. I Storbritannia har man også innført ordninger knyttet til fødselshjelp. Disse er for tiden under revidering fordi betalingsfordelingen mellom de ulike leverandørene som deltar i fødselshjelpen, har skapt logistiske utfordringer (묘).

\section{«En viktig utfordring $i$ det videre utviklingsarbeidet $i$ Norge er å utvide forløpene til å gjelde tjenester på tvers av helseforetak»}

I 2017 fikk Helsedirektoratet i oppdrag fra Helse- og omsorgsdepartementet å legge frem forslag til nye finansieringsmodeller til bruk i den norske helsetjenesten. Som et resultat ble det i 2019 innført forløpsbasert betaling for dialyse og fire kostnadskrevende behandlingsprogrammer, såkalte tjenesteforløpsgrupper (tabell 2). Refusjonen for disse gruppene er basert på historisk aktivitet over en gitt tidsperiode. Dette skal gi leverandørene økonomiske insentiver til å velge den minst kostbare behandlingen, noe 
som i de fleste tilfeller vil bety pasientadministrert behandling. For dialyse gir den gjennomsnittsbaserte prisingen $ø$ kt insentiv til å foreta dialyse i hjemmet i stedet for ved en institusjon (19).

\section{Tabell 2}

Eksisterende forløpsbasert finansiering tilbudt i det norske helsevesenet. All informasjon er hentet fra www.helsedirektoratet.no/tema/finansiering.

\begin{tabular}{|ll|}
\hline Tjenesteforløp & Beskrivelse \\
\hline Hofte- og kneprotesekirurgi & $\begin{array}{l}\text { Full hoftekirurgi, konsultasjoner før og etter inngrepet og } \\
\text { fastsatt innleggelsesperiode }\end{array}$ \\
\hline Hudlidelser & $\begin{array}{l}\text { Sykdomsmodifiserende medisinsk behandling. Ettårig } \\
\text { pakkeforløp for alle kostnader til medisiner under } \\
\text { behandling både på sykehus og hjemme }\end{array}$ \\
\hline Dialyse & $\begin{array}{l}\text { Dialysebehandling. Én måneds pakkeforløp med både } \\
\text { hemodialyse og peritoneal dialyse, behandling både på } \\
\text { sykehus og hjemme }\end{array}$ \\
\hline Revmatologiske lidelser & $\begin{array}{l}\text { Sykdomsmodifiserende medisinsk behandling. Ettåring } \\
\text { pakkeforløp for alle kostnader til medisiner under } \\
\text { behandling både på sykehus og hjemme }\end{array}$ \\
\hline Mage- og tarmlidelser & $\begin{array}{l}\text { Sykdomsmodifiserende medisinsk behandling. Ettåring } \\
\text { pakkeforløp for alle kostnader til medisiner under } \\
\text { behandling både på sykehus og hjemme }\end{array}$ \\
\hline Nevrologiske lidelser & $\begin{array}{l}\text { Sykdomsmodifiserende medisinsk behandling. Ettåring } \\
\text { pakkeforløp for alle kostnader til medisiner under } \\
\text { behandling både på sykehus og hjemme }\end{array}$ \\
\hline
\end{tabular}

I 2020 ble det også innført en forløpsbasert finansieringsordning for hoftekirurgi. I denne ordningen gjelder refusjonen for kjernen av forløpet, inkludert kirurgi og tilknyttede polikliniske tjenester før og etter innleggelse. Pasientene stratifiseres i to risikogrupper. Rehabilitering er utelatt fra modellen for å gjøre risikoen minst mulig for deltagerne og

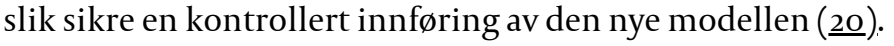

En viktig utfordring i det videre utviklingsarbeidet i Norge er å utvide forløpene til å gjelde tjenester på tvers av helseforetak og å håndtere tjenester der det ikke er fast ansvarsdeling mellom primær-og spesialisthelsetjenesten. Mangelen på konkurranse innenfor et offentlig system kan også være en utfordring. Det kan hevdes at leverandører har større insentiver til å bevise sin verdi og konkurrere på grunnlag av kostnader og kvalitet i et system med flere betalere, slik som det nederlandske. I et offentlig finansiert system vil det imidlertid være betydelig enklere å innføre obligatoriske forløpsbaserte finansieringsordninger på nasjonalt eller regionalt nivå. Fritt behandlingsvalg-reformen fra 2015 legger også til rette for utprøving av prinsippene bak forløpsbasert finansiering. Ordningen er etablert slik at de private tjenesteleverandørene har større oppfølgingsansvar, for eksempel ved å forutsette at håndtering av komplikasjoner og annen oppfølging inngår i tjenesten det betales for.

\section{Konklusjon}


USA har et presserende behov for å snu trenden med stadig økende kostnader i helsetjenesten. Introduksjonen av forløpsbasert finansiering er slik sett et vesentlig skifte for landet, og det er i dag tydelige tegn på at amerikanerne er på vei bort fra detaljert stykkprisfinansiering og mot alternative refusjonsordninger der kvalitet belønnes mer enn kvantitet. Det gjenstår likevel å se om innføringen av forløpsbaserte finansieringsordninger vil være avgjørende for å snu kostnadstrenden.

Til tross for at utfordringene og insentivene innenfor et offentlig finansiert system er svært forskjellige fra dem man finner i USA, tyder mye på at forløpsbasert finansiering kan komme til å spille en viktig rolle i fremtidens norske helsetjeneste. Det er behov for å etablere mer sømløse pasientforløp i et system som fortsatt preges av «siloer» og splittelse mellom ulike aktører i helsetjenesten. Med sterke tradisjoner for å samle inn kvalitetsdata og samtidig store ambisjoner om å etablere mer integrerte elektroniske pasientjournalsystemer synes den norske helsetjenesten å være godt rustet for innføringen av forløpsbaserte finansieringsordninger.

Det er likevel et tydelig behov for forskning på området. Vi trenger å lære mer om hvordan ordningen best kan tilpasses norske forhold og hvilke type modeller som fungerer best $i$ en offentlig finansiert helsetjeneste.

\section{LITTERATUR}

1. Meld. St. 7 (2019-2020). Nasjonal helse- og sykehusplan 2020-2023.

https://www.regjeringen.no/no/dokumenter/nasjonal-helse--og-sykehusplan-2020-2023/id2679013/ Lest 14.8.2020.

2. Byrkjeflot H, Torjesen DO. Managerial innovation in health care. The introduction, translation and use of the American DRG system in the hospital sector in Norway and Denmark. Mysterion, strategike og kainotomia 2010: 130-48.

3. Chilingerian J. Origins of DRGs in the United States: A technical, political and cultural story. The Globalization of Managerial Innovation in Health Care 2008: 4-33.

4. Chan L. The state-of-the-science: challenges in designing postacute care payment policy. Arch Phys Med Rehabil 2007; 88: 1522-5. [PubMed][CrossRef]

5. Mihailovic N, Kocic S, Jakovljevic M. Review of diagnosis-related group-based financing of hospital care. Health Serv Res Manag Epidemiol 2016; 3: 2333392816647892. [PubMed][CrossRef]

6. Mayes R. The origins, development, and passage of Medicare's revolutionary prospective payment system. J Hist Med Allied Sci 2007; 62: 21-55. [PubMed][CrossRef]

7. Burstin H, Leatherman S, Goldmann D. The evolution of healthcare quality measurement in the United States. J Intern Med 2016; 279: 154-9. [PubMed][CrossRef]

8. Obama B. United States Health Care Reform: Progress to Date and Next Steps. JAMA 2016; 316: 52532. [PubMed][CrossRef]

9. U.S. Centers for Medicare and Medicaid Services. Innovation Models.

https://innovation.cms.gov/innovation-models\#views=models Lest 14.8.2020.

10. LaPointe J.36\% of Payments Tied to Alternative Payment Models in 2018. RevCycleIntelligence: Xtelligent Healthcare Media 24.10.2019. https://revcycleintelligence.com/news/36-of-payments-tied-toalternative-payment-models-in-2018 Lest 14.8.2020.

11. Struijs JN, Hayen A, van der Swaluw K. When designing bundled payments, don't ignore the lessons of behavioral economics. Health Affairs 25.4.2018. https://www.healthaffairs.org/do/10.1377/hblog20180420.640240/full/ Lest 14.8.2020.

12. Agarwal R, Liao JM, Gupta A et al. The impact of bundled payment on health care spending, utilization, and quality: A systematic review. Health Aff(Millwood) 2020;39: 50-7. [PubMed] [CrossRef]

13. Joynt Maddox KE, Orav EJ, Zheng J et al. Evaluation of Medicare's bundled payments initiative for medical conditions. N Engl J Med 2018; 379: 260-9. [PubMed][CrossRef] 
14. Navathe AS, Shan E, Liao JM. What have we learned about bundling medical conditions? Health Affairs Blog 28.8.2018. https://www.healthaffairs.org/do/10.1377/hblog20180828.844613/full/ Lest 14.8.2020.

15. Zhu JM, Patel V, Shea JA et al. Hospitals using bundled payment report reducing skilled nursing facility use and improving care integration. Health Aff(Millwood) 2018; 37:1282-9. [PubMed] [CrossRef]

16. Pross C, Geissler A, Busse R. Measuring, reporting, and rewarding quality of care in 5 nations: 5 Policy levers to enhance hospital quality accountability. Milbank Q 2017; 95: 136-83. [PubMed] [CrossRef]

17. Struijs JN. How bundled payments are working in the Netherlands. Harvard Business Review 12.10.2015. https://hbr.org/2015/10/how-bundled-health-care-payments-are-working-in-the-netherlands Lest 14.8.2020.

18. Better ways to pay for health care. OECD Health Policy Studies. Paris: OECD, 2016. https://www.oecd.org/els/health-systems/Better-ways-to-pay-for-health-care-FOCUS.pdf Lest 14.8.2020.

19. Tjenesteforløp som grunnlag for Innsatsstyrt finansiering. Beskrivelse av videre arbeid. Oslo: Helsedirektoratet, 2018.

20. Innsatsstyrt finansiering 2020. IS-2869. Oslo: Helsedirektoratet, 2020. https://www.helsedirektoratet.no/tema/finansiering/innsatsstyrt-finansiering-og-drgsystemet/innsatsstyrt-finansiering-isf/ISF-regelverket\%202020.pdf/_/attachment/inline/oa14f8c6-24434c22-97ce-df83d54ff27e:97c7d54f4o8ce454ebd38caa957d3e4e8c40a7bo/ISF-regelverket\%2O2O20.pdf Lest 14.8.2020.

Publisert: 20. august 2020. Tidsskr Nor Legeforen. DOI: 10.4045/tidsskr.20.0367

Mottatt 23.4.2020, første revisjon innsendt 26.5.2020, godkjent 14.8.2020.

(C) Tidsskrift for Den norske legeforening 2023. Lastet ned fra tidsskriftet.no 26. april 2023. 